\title{
Effect of Welding Parameters on Hot Cracking Susceptibility of Alloy 800*
}

\author{
By M.B. Zaghloul ${ }^{* *}$, A.A.Sadek***, A.M. El-Batahgy*** and M. Hanafy ${ }^{* * * *}$
}

\begin{abstract}
The varestraint cracking test was carried out to assess the hot cracking tendency of alloy 800 at different welding conditions and augmented strain levels. The test results revealed that the hot cracking susceptibility of alloy 800 increases with increasing the heat input and augmented strain levels. This emphasizes the role of constraint either internally induced or externally applied to the welded structure.

A cracking threshold or the minimum augmented strain $\left(\boldsymbol{\epsilon}_{\min }\right)$ below which no hot cracking takes place has been found to be 0.25 for alloy 800. Also, the Critical Strain Rate to Time (CSS) required to cause cracking was found to be $6.42 \times 10^{-3} \mathrm{sec}^{-1}$ at welding condition of $100 \mathrm{Amp}, 13$ Volt and $140 \mathrm{~mm} / \mathrm{min}$.
\end{abstract}

Key Words: Austenitic Stainless Steels, Weld Metals, Hot Cracking, Solidification, Weldability Tests

\section{Introduction}

Alloy 800 is an iron-based, fully austenitic alloy, which is often selected for use in high temperature environments where a combination of strength and corrosion resistance is required. It has been used extensively by the nuclear power industry for superheater and reheater tubes and, more recently, has been chosen by the solar energy industry for solar central receiver panels in multi-kilowatt power plants. For most applications alloy 800 is welded using a high Nickel filler material to minimize fusion zone hot cracking.

However, it is often necessary to perform autogenous (fillerless) welds as in the case of tube-to header welds or when joining thin sheets. The reliability of these welds is generally good in comparison to other fully austenitic stainless steels. However, several investigations have reported that this alloy is susceptible to cracking in either fusion zone or the terminal weld crater $^{1-3)}$.

The purpose of this study was to evaluate quantitatively the effect of welding parameters and augmented strain on the hot cracking susceptibility and to propose after, the mechanism of hot cracking phenomena of this alloy. In this study, the varestraint test was carried out to assess the effect of augmented strain.

\section{Experimental Procedure}

\subsection{Material}

The chemical composition of alloy 800 used in this work is listed in Table 1. The as-recieved material was in the form of pipe of $900 \mathrm{~mm}$ diameter and $3 \mathrm{~mm}$ wall thickness. The microstructure is fully austenitic fine grained matrix

Table 1 Chemical analysis of alloy 800 (mass\%).

\begin{tabular}{llllllllllll}
\hline $\mathrm{Ni}$ & $\mathrm{Cr}$ & $\mathrm{Fe}$ & $\mathrm{C}$ & $\mathrm{Mn}$ & $\mathrm{S}$ & $\mathrm{Si}$ & $\mathrm{Cu}$ & $\mathrm{A} 1$ & $\mathrm{Ti}$ & $\mathrm{P}$ \\
\hline 32.3 & 21.65 & 43.51 & 0.05 & 0.77 & 0.004 & 0.24 & 0.52 & 0.48 & 0.46 & 0.018 \\
\hline
\end{tabular}

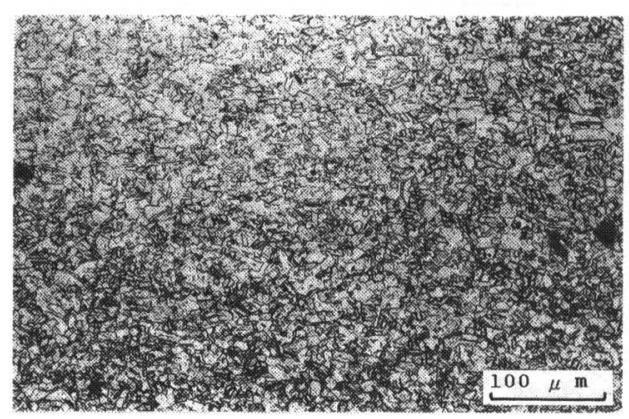

Fig. 1 Microstructure of the as recieved alloy 800 .

\footnotetext{
* Received : 30 August 1993.

** Prof. Dr. Head of Welding Research Department, CMRDI

*** Dr. Eng. Researcher at WRD, CMRDI

**** Eng, Lecturer Assistant at WRD, CMRDI, EGYPT
} 
with some undissolved carbides precipitation at grain boundaries, Fig. 1.

\subsection{Varestraint Test}

In general, over thirty different cracking tests have been developed, most of those testing processes are limited in applicability and the analysis of strain producing cracking is almost impossible by them. It is essential that the strain be known quantitatively to investigate the strain tolerance of the microstructure. Tests with externally applied strains during solidification of weld metal offer the best chance of strain measurement. For this purpose the varestraint test was employed to determine the relative hot cracking susceptibility of the commercial alloys. Varestraint test specimens were cut and straightened each $25 \times 4 \times 0.3 \mathrm{~cm}$. Specimens were tested in the varestraint apparatus over a range of augmented strains from 0.25 to $4 \%$. The augmented strain, $\epsilon$, is given by the following relationship :

$$
\epsilon \%=\mathrm{t} / 2 \mathrm{R} \times 100
$$

Where, $\mathrm{t}$ is the specimen thickness, and $\mathrm{R}$ is the radius of the die block over which the specimen is bent.

Figure 2 shows the arrangement of testing machine. A specimen is held over a radius removable die-block as a cantilever beam and a TIG arc melt run (bead on plate) is made along the center line. Preliminary tests revealed that the hot
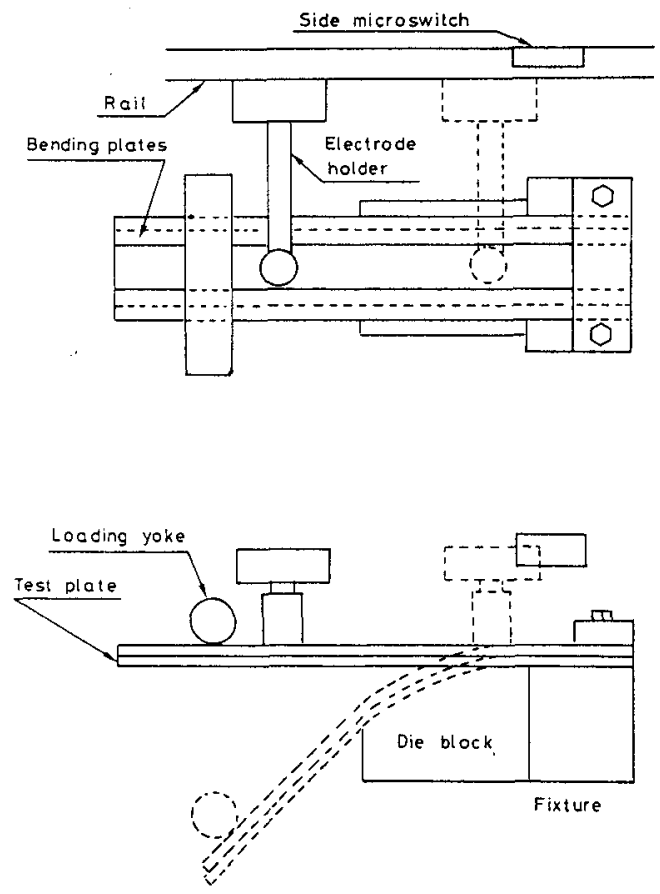

Fig. 2 Schematic illustration of the testing machine.
Table 2 Welding Conditions.

\begin{tabular}{|c|c|c|}
\hline $\begin{array}{l}\text { Welding Current } \\
\text { (Amp) }\end{array}$ & $\begin{array}{c}\text { Travel Speed } \\
(m n / s)\end{array}$ & $\begin{array}{c}\text { Arc Voltage } \\
\text { (volts) }\end{array}$ \\
\hline 90 & $2.3 \notin 2.7$ & 13 \\
\hline 100 & $2.3 \div 2.7$ & 12 \\
\hline 110 & $2.3 \& 2.7$ & 13 \\
\hline 120 & $2.3 \& 2.7$ & 13 \\
\hline
\end{tabular}

cracking produced by the varestraint testing procedure is invariably adjacent to, and usually contiguous with, the location of the weld puddle at the instant of application of the augmented strain. Thus, at a predetermined point the specimen is rapidly bent around the die block by a hydraulically activated loading yoke, inducing strain. The dropping rate of the loading yoke was about $80 \mathrm{~mm} / \mathrm{s}$ on an average for $6600 \mathrm{Kg}$ load under loading of various specimens used in this investigation. The welding conditions used during the varestraint test are listed in Table 2.

A trailing shielding gas was employed on the GTA torch during the test to minimize oxidation of the region where cracks form and subsequently facilitate the measurement and tabulation of cracking data.

Crack tabulation was performed on the aswelded surface and polished surface of the specimen with the aid of a profile projector. All crack measurements were performed at $50 \times$ to $100 \times$ magnification, in both the as welded condition and after polishing to the plate surface, for evidence of solidification cracking in the weld metal. Both the length and number of all cracks present are recorded. In some instances, a section of the test specimen containing all of the cracks produced by the augmented strain was removed, mounted and metallographically polished. Samples were etched with aqua rejia and oxalic acid was also used for electrolytic etching.

\section{Results and Discussion}

Four criteria are used to evaluate the test results :

(1) Cracking threshold: since the inherent restraint provided by the simple rectangular specimen is too low to cause cracking. The maximum augmented strain above which cracks occur with a given set of welding parameters provides one quantitative index of cracking sensitivity, called the cracking threshold. In addition, the variation of the cracking threshold produced by changes in welding process and welding parameters provides a quantitative method for comparing welding procedures effects. 
(2) Maximum crack length, has been found to provide a useful qualitative index of cracking sensitivity. Measurements of maximum crack length at comparable levels of augmented strain can therefore be used as a rapid screening technique during preliminary testing of materials, provided a constant puddle geometry is maintained.

(3) Number of cracks observed in whole weld metal, providing another quantitative index for comparing hot cracking susceptibility.

(4) Total crack length, which is the sum of the lengths of all the cracks observed. The total crack length has proved to be the best quantitative index of the cracking susceptibility of the weld material. Comparison of total length values also provides a uesful method for comparing the effect of changes in welding procedure with given material.

\subsection{Effect of Welding Conditions on Hot Crack- ing Susceptibility}

The typical examples of cracking modes on weld metal surfac of alloy 800 are shown in Fig. 3 for augmented strain levels of $2 \%$ and $4 \%$ at
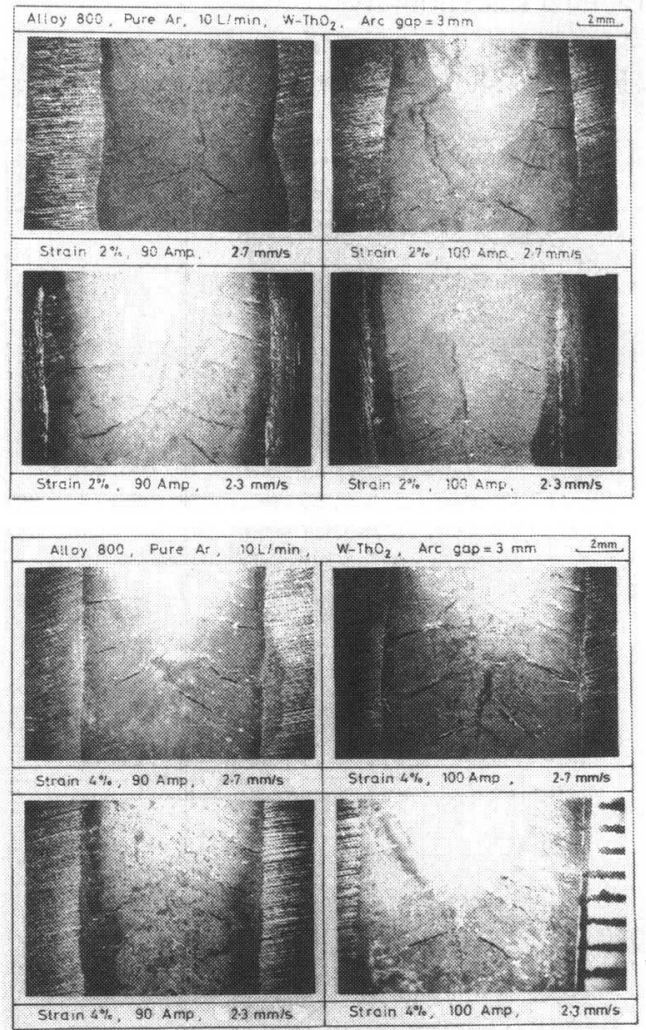

Fig. 3 Cracking modes on weld metal surface of alloy 800 for augmented strain levels of $2 \%$ and $4 \%$ at different welding conditions. different welding conditions, or in other words at different levels of heat input.

At lower strain level, and lower level of heat input many of small cracks originated near the fusion boundaries within the weld metal. Generally, cracks appeared in the perpendicular direction to the ripple line at the instant the augmented strain was applied. Subsequently, with an increase of heat input by increasing welding current at same welding speed and augmented strain level, the number of cracks increased along the ripple line, and the length of each crack also increased toward inward location. The same behavior can be observed at all of test conditions, with increasing the augmented strain level at same value of heat input. Figure 4 shows the effect of heat input on the total crack length and the maximum crack length at different augmented strain level, respectively.

Here it is important to note that there are different types of hot cracking, mainly, solidification cracking, HAZ liquation cracking and ductility-dip cracking. Each cracking has a different cracking mechanism ;

a) solidification cracking occurs within a few hundred degrees of the nominal liquidus temperature of the weld metal and is induced by welding stresses or under augmented strain and the pres-
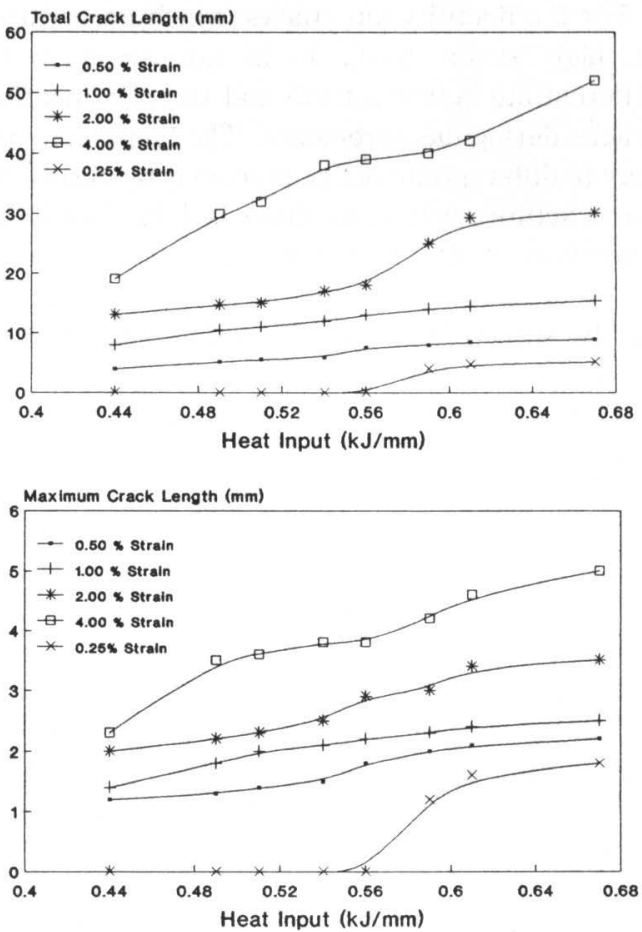

Fig. 4 Effect of heat input on the total crack length and maximum crack length. 
ence of low melting point constituents that from as a result of segregation during the liquid-to solid-phase transformation process.

b ) HAZ liquation cracking, is another type of high-temperature cracking. Localized liquation of low melting point constituents such as foreign inclusions, carbide phases, or local segregations of certain alloying elements in the solid may form liquid grain boundary films. The attendant welding strain may, in turn, be sufficiently high to open liquation cracks.

c) Ductility-dip cracking, this type of crack forms while the weld cools through a range of temperatures where the ductility of the particular metal is inherently low. The ductility-dip temperature for austenitic stainless steels fall just below the recrystallization temperature. If sufficiently high strain is present as the metal cools through the ductility-dip temperature range, cracking occurs. From these points of view, and in this investigation, at lower strain only a small solidification cracks were observed because the strain was not enough to create the other two types. At higher strain level the HAZ liquation cracking with very small size was observed specially with higher amount of heat input. In that case, all measurements had been done in the weld metal area only and did not extended to the HAZ area.

For the ductility-dip cracks, which occurs also at high strain level, it is not so easy to differentiate between them and the solidification cracks during measurements. The fundamentally way to differentiate between them is by observing the fracture surface as described in details by Pumphrey et $\mathrm{al}^{4}$. . Also, they were concluded that alloys susceptible to solidification cracking may not be susceptible to ductility-dip cracking and the converse may also be true. Thus in this investigation, if small amount of ductility-dip cracks were occurred at high amounts of strain and heat input, it was measured as solidification cracks.

Noting that, in case of $0.25 \%$ augmented strain, no cracks appeared until the welding condition of $120 \mathrm{Amp} \& 2.7 \mathrm{~mm} / \mathrm{s}$, at which the first crack was detected.

The observed differences in total crack length and maximum crack length at different welding conditions could be attributed to the quantity and location of segregations, remaining after solidification of the bulk and possibly to the grain boundary wetting characteristics, in determining the extent of grain boundary liquation and (racking ${ }^{5}$.
Obviously, at lower amount of heat input the amount of segregation produced, such as low melting elements like $\mathrm{P}$ and $\mathrm{S}$ or low melting carbide phases, is smaller than that obtained at higher amount of heat input. Therefore, cracking response in the latter case will be higher due to the changes of weld pool shape and to the increase in heat input which lead to lower cooling rate, wider liquidus-solidus range, coarser cell size and high amount of segregation, as well as the change in stress distribution at trailing edge of the weld pool as a function of temperature gradient around the weld pool ${ }^{6,7)}$.

Figure 5 shows typical examples of the solidification microstructure near the cracks at different welding conditions at same level of the augmented strain (2\%). It is obvious to say :

1 - Hot cracking in alloy 800 verestraint test speciments is restricted to dendrite column boundaries.

2-With increasing the heat input, the solidification structure is changed, i.e. at lower heat input the solidification structure is finer than that at higher heat input. This can explain the above mentioned effect of heat input on the hot cracking susceptibility.

\subsection{Effect of Augmented Strain}

Figure 6 shows the effect of augmented strain

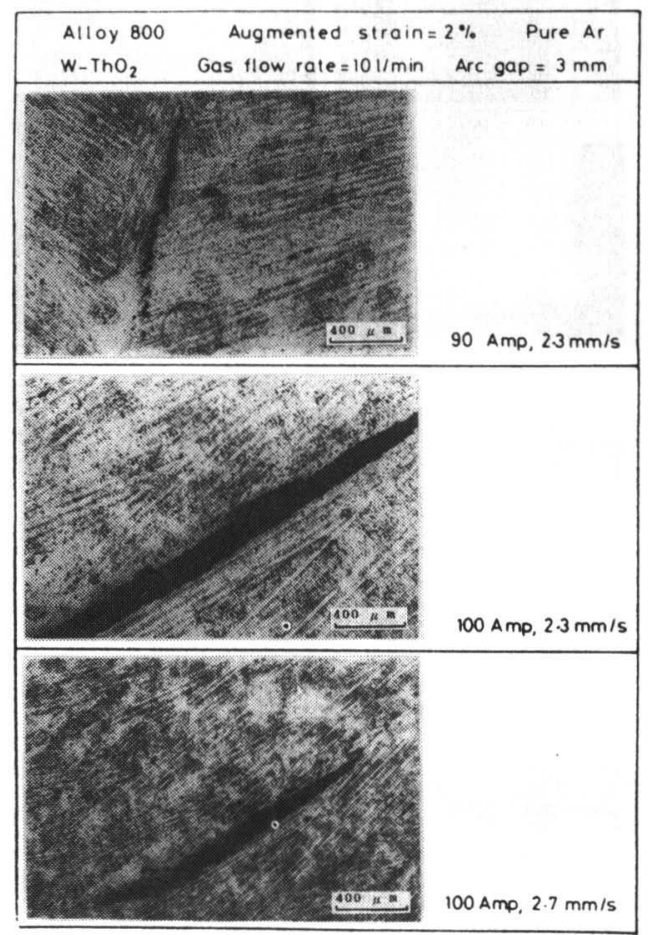

Fig. 5 Effect of heat input (welding conditions) on solidification microstructures at $2 \%$ augmented strain. 

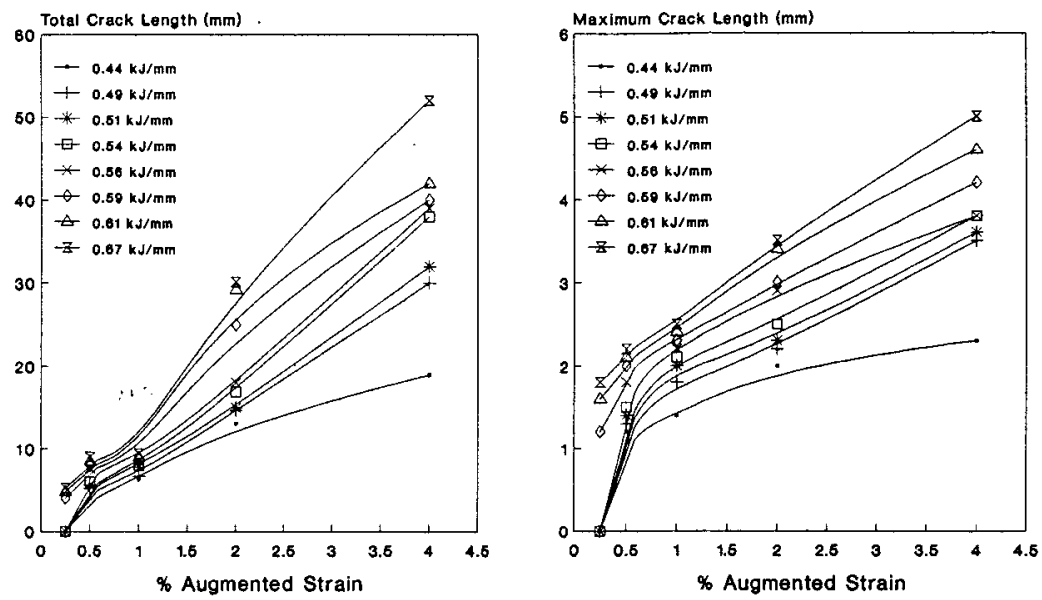

Fig. 6 Effect of augmented strain on total crack length and maximum crack length.

on the total crack length and the maximum crack length for weld metal under different welding conditions (different levels of heat input). It is clearly shown that the total crack length and maximum crack length increase with the increase in augmented strain level. The total crack length and maximum crack length were zero at the lowest augmented strain used $(0.25 \%)$.

Also, it can be noticed that at low levels of augmented strains $(0.5$ and $1 \%)$ the increase in total crack length with augmented strain levels takes place at a slow rate without a big difference in total crack length, whereas, at higher levels of augmented strain a drastic increase in total crack length was observed.

Moreover, with increasing the amount of heat input at augmented strain level of $0.25 \%$ the maximum crack length and total crack length were increased. This can be explained as follows; increasing the heat input results in a wider zone of plastic yielding and causes a larger volume of metal to expand, which on subsequent contraction will increase shrinkage stresses, which in turn, increase the cracking susceptibility even at low level of augmented strain.

However, an important index of hot cracking susceptibility measurement can be resulted from the relation between maximum crack length and augmented strain. This index is the Critical Strain Rate to Time (CSS) below which a crack would not occur. The values of (CSS) are directly calculated from the curve, as schematically shown in Fig. 7. The inclination between the vertical axis, which is revised from length to time by means of division by welding speed, and straight line, which is tangentially drawn from the origin to the curve, shows the value of the

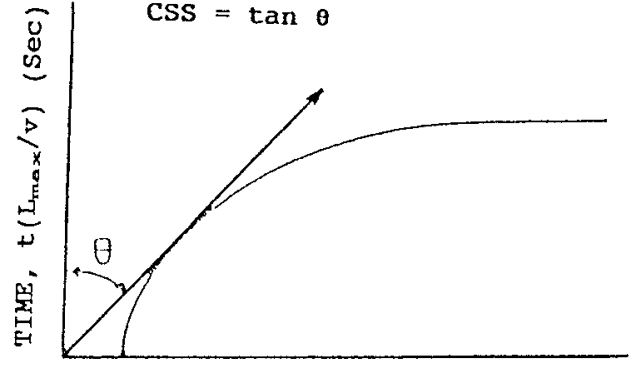

AUGMENIED STRAIN, $E$ ( $(z)$

Fig. 7 Estimation of CSS crack susceptibility index from the relationship between maximum crack length and percent aug. mented strain.

(CSS) for each welding condition.

Noting that in case of varestraint tests some researches recommended the adoption of the total length of cracks instead of the maximum length of crack. However, Y. Arata et $\mathrm{al}^{8)}$ had done supplemental tests for comparing the results of CSS with the difference between the maximum length of crack obtained by the longitudinal and transverse verestraint tests and they found that the results of calculation were almost same for the two types of varestraint tests. Therefore, the maximum crack length is convertible between the two varestraint tests at high strains.

From this point of view the values of the (CSS) were calculated and shown in Table 3 for different welding conditions. It can be concluded that, the critical strain rate to time (CSS) above which crack occurs, in case of alloy 800 is $6.4 \times$ $10^{-3}(1 / \mathrm{sec})$ at the currently used welding condition of $100 \mathrm{Amp}$ and $2.3 \mathrm{~mm} / \mathrm{s}$. Table 4 shows a comparison between the (CSS) values of alloy 
Table 3 CSS values of alloy 800 at different welding conditions.

\begin{tabular}{llr}
\hline welding Condition & $\tan \theta(1 / \mathrm{mm})$ & $\operatorname{CSS}(\mathrm{S} \tan \theta) 1 / \mathrm{sec}$ \\
\hline $100 \mathrm{~A}-2.7 \mathrm{~mm} / \mathrm{s}$ & $3.38 \times 10^{-3}$ & $10.2 \times 10^{-3}$ \\
$90 \mathrm{~A}-2.3 \mathrm{~mm} / \mathrm{s}$ & $3.53 \times 10^{-3}$ & $8.2 \times 10^{-3}$ \\
$110 \mathrm{~A}-2.7 \mathrm{~mm} / \mathrm{s}$ & $3.33 \times 10^{-3}$ & $8.88 \times 10^{-3}$ \\
$100 \mathrm{~A}-2.3 \mathrm{~mm} / \mathrm{s}$ & $2.75 \times 10^{-3}$ & $6.42 \times 10^{-3}$ \\
\hline
\end{tabular}

Table 4 Summary of evaluated hot cracking susceptibiliry.

\begin{tabular}{lrr}
\hline Material & CSS $(1 / \mathrm{sec})$ & welding Condition \\
\hline Alloy 800 & $6.4 \times 10^{-3}$ & $13 \mathrm{~V}-100 \mathrm{~A}-2.3 \mathrm{~mm} / \mathrm{s}$ \\
AISI 304 & $65.0 \times 10^{-3}$ & $18 \mathrm{~V}-250 \mathrm{~A}-2.5 \mathrm{~mm} / \mathrm{s}$ \\
AISI 316 & $4.0 \times 10^{-3}$ & $18 \mathrm{~V}-250 \mathrm{~A}-2.5 \mathrm{~mm} / \mathrm{s}$ \\
AISI 310 & $2.1 \times 10^{-3}$ & $18 \mathrm{~V}-250 \mathrm{~A}-2.5 \mathrm{~mm} / \mathrm{s}$
\end{tabular}

800 and other alloys taken from other studies ${ }^{9)}$. From this table, it can be said that hot cracking susceptibility of alloy 800 laying between that of AISI 310 and AISI 304 and nearly equal to that of AISI 316.

From the above results, it can be also said that the cracking threshold strain for alloy 800 is $0.25 \%$ augmented strain. Because under a wide range of welding conditions, no cracks were observed at augmented strain level of $0.25 \%$.

\subsection{Hot Cracking Mechanism}

Based on the above experimental results, the following mechanism could be proposed:

- On solidification, the amount of the primary solid increases with the decrease in temperature below melting point, at the expense of the liquid which will be trapped between the solidifying grains.

- When the solid forms a semi-continuous network, the liquid movement is rather blocked and the strain will be transmitted to the liquid between the dendrites.

- If the applied strain level is higher than the cracking threshold strain of the material, hot cracking will take place between the interlocked dendrite, having an intergranular appearance, as shown in Fig. 8.

Therefore, this mechanism can be briefly explained in the following points :

(1) During the terminal stages of solidification, ductility of the material reaches a minimum.

(2) The liquid metal interlocked between dendrites making it the weakest point of the structure. This liquid metal contains most of the low melting point segregates as $\mathrm{P}$ and $\mathrm{S}$.

(3) If a certain amount of strain is applied to the material, it will be transmitted and concentrated at these weakest points and tends to open up gaps between dendrites, The strain acting on

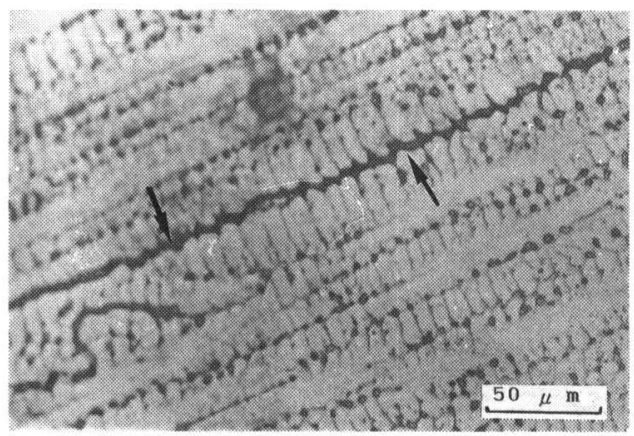

Fig. 8 Intergranular appearance of hot cracking which takes place between the interlocked dendrite.

the weld, is partially originating from thermal contraction or solidification shrinkage or both. Other strains could also be externally applied to the weld area and forces it to contract or distort. This takes place only in heavy constructions.

(4) The applied strain required to open the first crack should be higher than the cracking threshold strain of the material $\left(\epsilon_{\min }\right)$.

\section{Conclusions}

The effect of welding conditions on the hot cracking of alloy 800 at different augmented strain levels has been studied and the results may be summarized as follows:

(1) The hot cracking susceptibility increases with increasing the heat input. This may be attributed to the wider plastic yielding at HAZ with increasing heat input and resulting in higher shrinkage stresses on subsequent contraction. Also, the heat input affects the quantity and the location of the segregated particles remaining after the solidification of the bulk, and possibly the dendrite boundaries wetting characteristics.

(2) Hot cracking susceptibility increases as the percent of augmented strain increases. This was attributed to the increase in the degree of constraint.

(3) The cracking threshold strain or the minimum augmented strain $\left(\epsilon_{\mathrm{m} \text {.n }}\right)$ below which no hot cracking takes place was found to be $0.25 \%$ for alloy 800 , which is rather low indicating the high hot cracking susceptibility of this alloy.

(4) The critical strain rate to time required to cause cracking was found to be $6.42 \times 10^{-3} \mathrm{sec}^{-1}$ for welding condition of $100 \mathrm{Amp}, 13 \mathrm{Volt}$ and 2.3 $\mathrm{mm} / \mathrm{s}$, which can be considered to locate between AISI 310 and AISI 304 and nearly equal to AISI 316. 


\section{References}

1) Robert D.I., "Design code and life time prediction aspects for alloy 800 for nuclear and non-nuclear applications", General atomic Co. San Diago, California, USA. 1978.

2) Fricker H.W. and Mallen-Herrero J. "The use of alloy 800 in the THTR steam generator", BNES Materials Conference," Status review of alloy 800 ", Reading, Sep. 1974.

3) Ward M. and Norman P.L., "The welding of alloy 800 a review", BNES Materials Conference, "Status review of alloy 800", Paper No. 16, Sep. 1974.

4) Pumphrey W.I. and Moore D.C., "A consideration of the nature of brittleness at temperature below the solidus in casting and welds in aluminum alloys", $\mathrm{J}$. Inst. Metals, 1949.

5) Baeslack III, Lata W.P. and West S.L., "A study of heat affected-zone and weld metal liquation cracking in alloy 903", WRS, April, 1988.

6) Goodwin G.M.,"The effect of heat input and weld process on hot cracking in stainless steel", WRS, April, 1988.

7) Habachi G. and Marya S.K., "Effect of some GTAW process parameters on the solidification cracking of 304, 316L and 310 stainless steels", The 5th International Symposium of the Japan Welding Society, No. 5 JWS-IV-14, 1990.

8) Arata Y., Matsuda F. and Saruwatari S., "Varestraint test for solidification crack susceptibility in weld metal of austenitic stainless steel", Trans. of JWRI, Vol. 6, No. 2, 1977.

9) Senda T., Matsuda F., Takano G., Watanabe K., Kobayashi T. and Matsuzaka T., "Fundamental Investigation on Solidification Crack Susceptibility for Weld Metals with Trans-Varestraint Test", Trans. of Japan Welding Society, Vol. 2, No. 2, Sep. 1971. 